\title{
Heat Source for TIG Welding Modelling
}

\author{
Manahil Tongov \\ Faculty of Idustrial Technology \\ Technical University of Sofia \\ Center of Welding \\ Institute of Metal Science, Equipment \\ and Technologies with Hydro- \\ and Aerodynamics Centre "Acad. A. Balevski” \\ Bulgarian Academy of Sciences \\ Sofia, Bulgaria \\ tongov@tu-sofia.bg
}

\begin{abstract}
A new model of heat source applicable to TIG welding is proposed. The model uses three calibration parameters - efficiency, effective heating spot radius and heat source concentration factor. Based on the experimental results, the model was calibrated and the results obtained for the form of penetration were compared with the experimental ones
\end{abstract}

Keywords - TIG welding, modelling; heat source; calibrating parameters; calibrating methods; experimental results.

\section{INTRODUCTION}

One of the tasks that need to be solved within computer welding mechanics is thermal. Based on the obtained solution, such basic characteristics of the technological process are determined as: cooling time from $800\left[{ }^{\circ} \mathrm{C}\right]$ to $500\left[{ }^{0} \mathrm{C}\right] \mathrm{t}_{8 / 5}$; residence time of the metal above certain critical temperatures; obtained structures in the heat affected zone; determining the expected hardness in the joint area; the influence of the preheating temperature, determining the optimal one, etc. In addition, the solution of the thermal problem is the basis of the analysis of the obtained temporary and residual stresses, deformations and distortions in the welded structure. TIG welding is a widely used method in the welding of high-alloy corrosionresistant steels. One of the steps that needs to be implemented in the simulation modelling of the process is the calibration of the heat source model. The ISO / TS 18166 standard makes it possible to do this by welding specimens and experimentally determining the shape and dimensions of the melting zone. The mathematical model uses calibration parameters, which are determined in such way that the shape and dimensions of the melting zone calculated by solving the model correspond as much as possible to the experimentally obtained results. The welding mode parameters, geometric dimensions of the samples and thermal properties of the basic and additional materials cannot be used as calibrating parameters. This means that the calibration parameters in practice refer to the heat source and heat dissipation from the welded specimens. There are different heat sources models published (table 1 ) - surface [ $1 \div 9$ ], volume [10 $\div 21$ ], by combination of both types and those in which the modelling of the welding arc and the heating of the sample is calculated together [22 $\div 25]$. In TIG welding, the shape of the weld is usually obtained without inflection (Fig. 1a), but in some modes and mainly depending on the arc pressure, it is possible to obtain a curve with an inflection point (Fig. $1 b)$.

\section{HEATH SOURCE}

In this study a new heat source is proposed, which is suitable for welds without inflection and also a method for its calibration. The heat flux is represented by the superposition of two normally distributed heat sources:

$$
\begin{aligned}
& q(r)=q_{\text {eff }} \frac{A}{2}\left[\frac{1}{\sigma \sqrt{2 \pi}} \exp \left(-\frac{\left(r-r_{0}\right)^{2}}{2 \sigma^{2}}\right)+\right. \\
& \left.+\frac{1}{\sigma \sqrt{2 \pi}} \exp \left(-\frac{\left(r+r_{0}\right)^{2}}{2 \sigma^{2}}\right)\right]=q_{\text {eff }} A f(r)
\end{aligned}
$$

where $q_{\text {eff }}$ is the effective heat output, $f(r)$ is a heat flux distribution function and $\mathrm{A}$ is a norming multiplier to be determined by the condition 


$$
\int_{0}^{\infty} A f(r) 2 \pi r d r=1
$$

The final result for the norming multiplier is obtained after solving the last equation:

$$
A=\frac{1}{\sigma \sqrt{2 \pi} \exp \left(-\frac{r_{0}^{2}}{2 \sigma^{2}}\right)+\pi r_{0} e r f\left(\frac{r_{0}}{\sigma \sqrt{2}}\right)}
$$
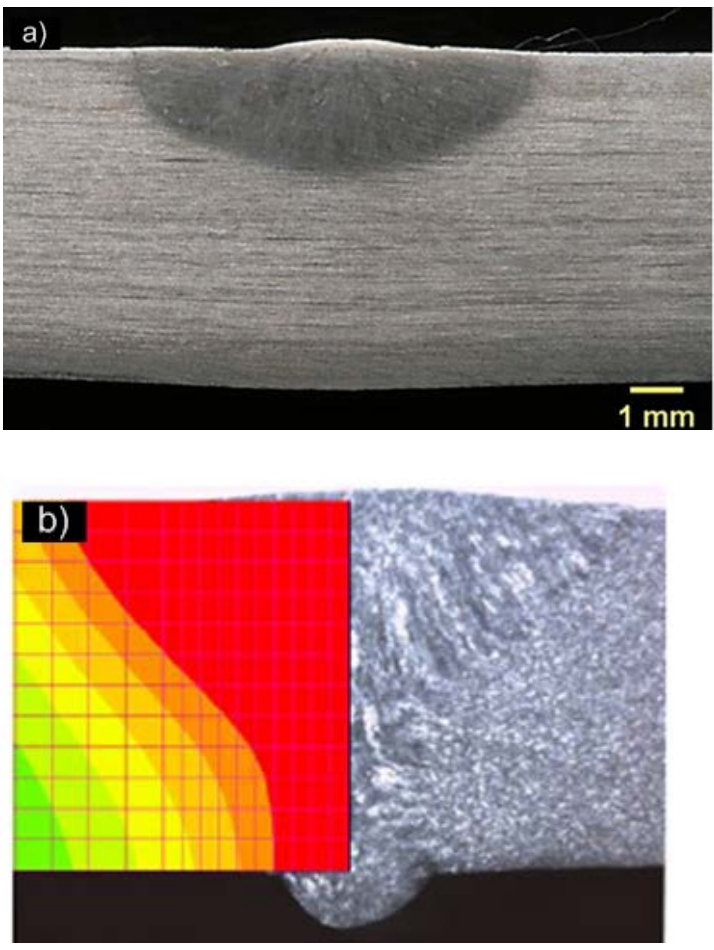

Fig.1. Two possible forms of penetration in TIG welding: seam shape without inflection point [26] - (a); weld shape with inflection [16] - (b).

For the use of the heat source it is convenient to define the effective heating radius $r_{a r c}$ and coefficient of deviation of the heat source from a normally distributed circular heat source $\alpha_{\text {arc }}=r_{0} / r_{\text {arc }}$ - distribution coefficient. These two parameters, as well as the efficiency, are determined by calibrating the thermal model in relation to the experimental results in the specific case of realization of the welding process. They determine $q_{\text {eff }}$ and. $\sigma=3 . r_{\text {arc }}$. At such selected ratios $r_{0} / \sigma=\alpha_{\text {arc }} / 3$. The influence of the coefficient $\alpha_{\text {arc }}$ on the heat flow distribution is shown in Fig.2.
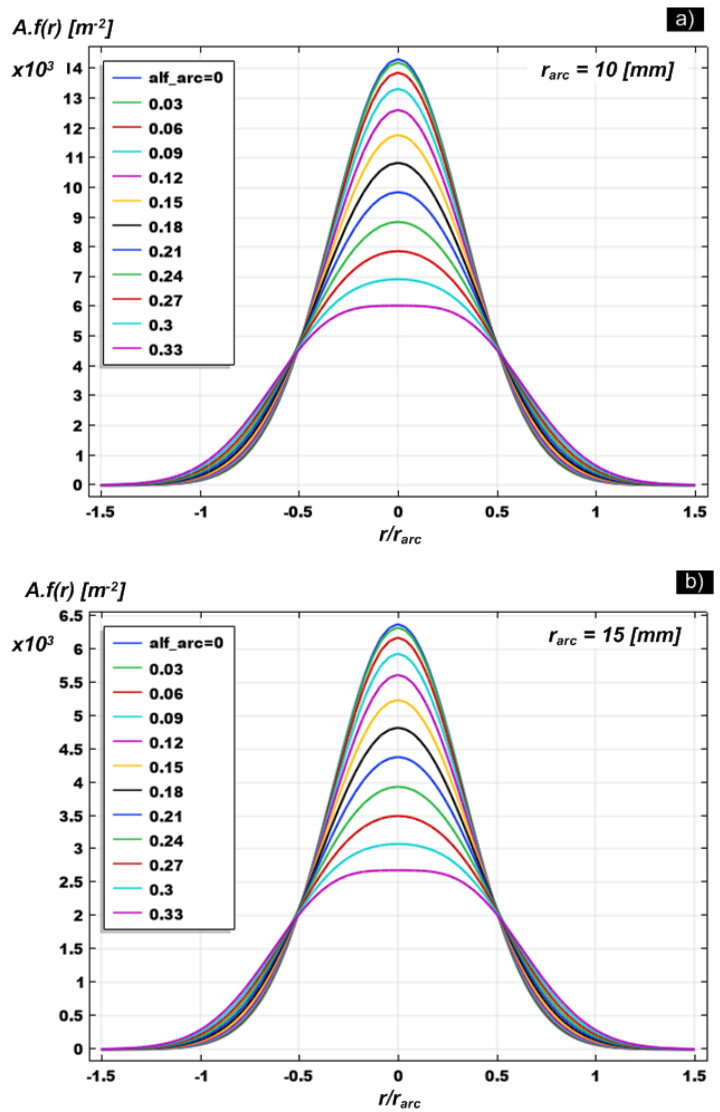

Fig.2. Influence of the heat source distribution coefficient on the heat flux density.

\section{METHODOLOGY FOR THE THERMAL MODEL CALIBRATION}

The calibration of the thermal model is performed by comparing experimental and simulation results. The simulation model must have calibration parameters to be determined on the basis of this comparison. The material characteristics, the geometry of the specimens and the parameters of the welding mode cannot be used as such. Usually the calibration parameters refer to the heat source. In this case, these are the efficiency $(\eta)$, the effective radius of the heating spot $\left(\mathrm{r}_{\text {arc }}\right)$, and the distribution coefficient $\left(\alpha_{\text {arc }}\right)$. The comparison of the experimental and numerical results can be performed on the basis of experimentally recorded temperature cycles at several points of the welded specimens or the shape of the penetration determined by metallographic analysis. In the considered example the second variant is used. Beads with the welding mode of interest are performed on a plate with a thickness equal to the thickness of the welded parts in the structure and from the same material from which the structure is made with dimensions sufficient to reach a quasi-stationary process (Fig.3). The depth of penetration $\left(\mathrm{h}_{\mathrm{p}}\right)$ and the width of the weld $\left(b_{\mathrm{w}}\right)$ are determined by making metallographic macrosection from the area of the established quasistationary process. 
Environment. Technology. Resources. Rezekne, Latvia Proceedings of the $13^{\text {th }}$ International Scientific and Practical Conference. Volume 3, 348-356

TABLE I. HEAT SOURCES.

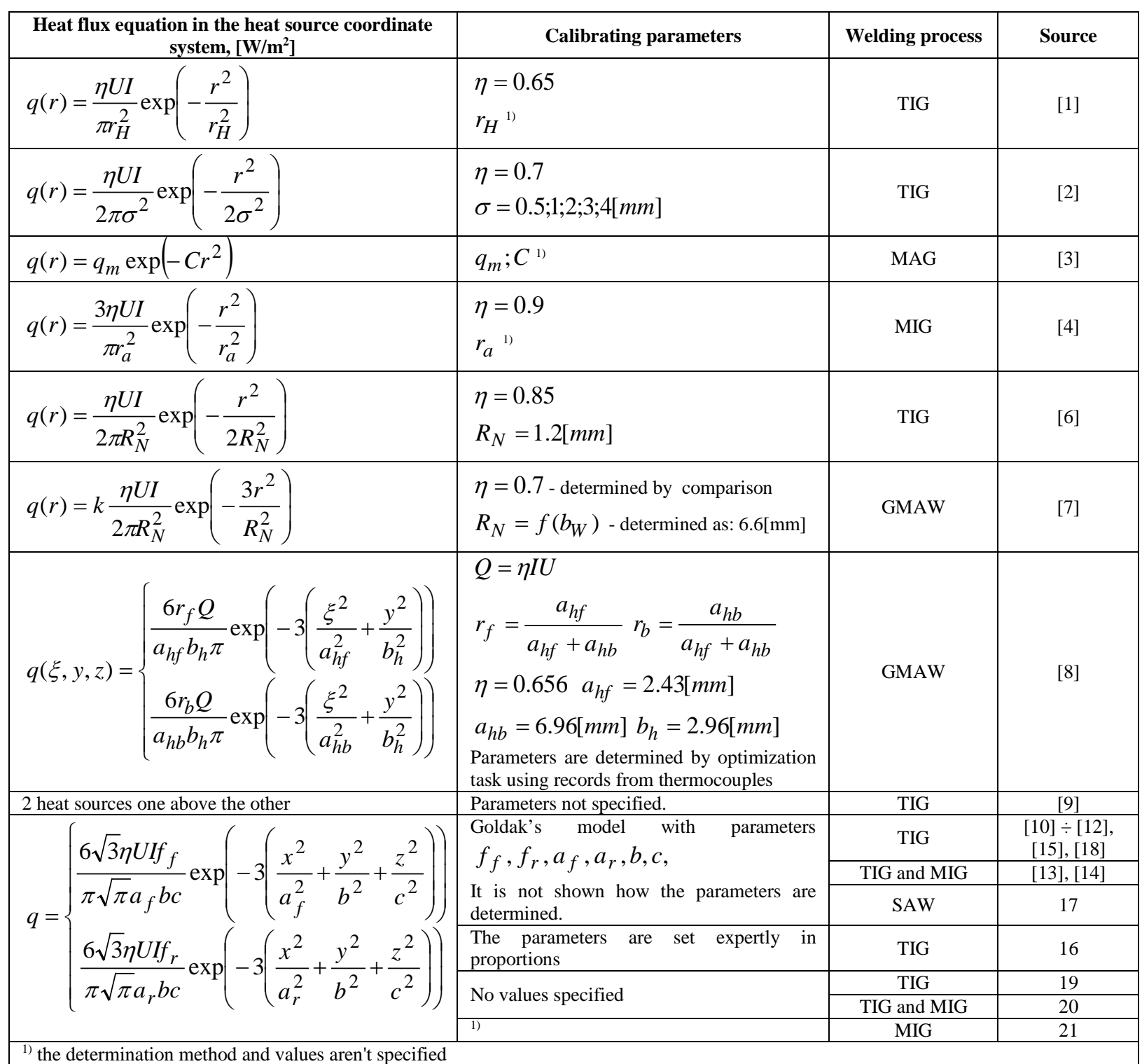

\section{$\operatorname{Tmax}[K]$}

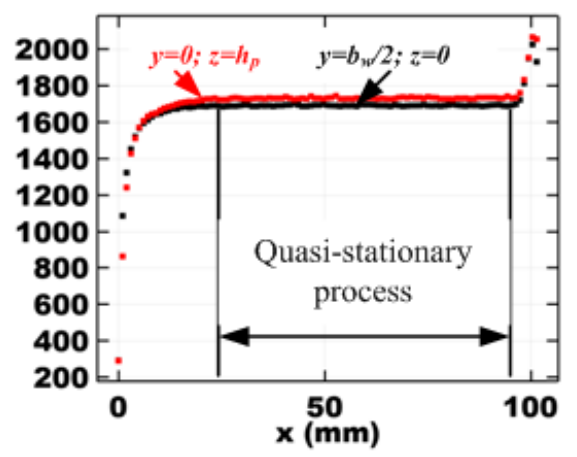

Fig.3. Maximum temperature reached for two lines parallel to the weld axis
A mathematical model is being developed to describe the realized welding process using the same geometry, material characteristics and welding mode. A simulation model is being realized, which solves the thermal task, and at the last moment of time for which the solution is performed, the heat source is in the zone of the quasistationary state. In the geometry of the model, two (or more) straight lines $\left(l_{1}\right.$ and $\left.l_{2}\right)$ are drawn, parallel to the axis of the weld (Fig.4). One of these lines $\left(l_{1}\right)$ is located in the upper plane of the welded specimens and is at a distance $\mathrm{b}_{\mathrm{w}} / 2$ from the weld axis (passes through the point representing the width of the weld). The second line $\left(l_{2}\right)$ is at a distance $h_{p}$ from the upper surface of the welded specimens (in the direction of the depth of penetration) in a plane passing through the weld axis and perpendicular to the upper surface of the welded specimens - passes through the point determining the depth of penetration. The 
temperature change along these two lines at the last moment of solving the task is shown in Fig.5. For this two lines the maximum of the temperatures for this moment are determined $-\mathrm{T}_{1 \max }$ and $\mathrm{T}_{2 \max }$. The calibration parameters are found by solving an optimization problem with the following objective function $\left(\mathrm{T}_{\mathrm{S}}\right.$ is the solidus temperature):

$$
\begin{aligned}
& \Phi\left(\eta, \alpha_{\text {arc }}, r_{\text {arc }}\right)=\left(\frac{T_{1 \max }-T_{S}}{T_{S}}\right)^{2}+ \\
& +\left(\frac{T_{2 \max }-T_{S}}{T_{S}}\right)^{2} \Rightarrow \min
\end{aligned}
$$

or

$$
\begin{aligned}
& \Phi\left(\eta, \alpha_{\text {arc }}, r_{\text {arc }}\right)= \\
& =\max \left(\left|\frac{T_{1 \max }-T_{S}}{T_{S}}\right|,\left|\frac{T_{2 \max }-T_{S}}{T_{S}}\right|\right) \Rightarrow \min
\end{aligned}
$$

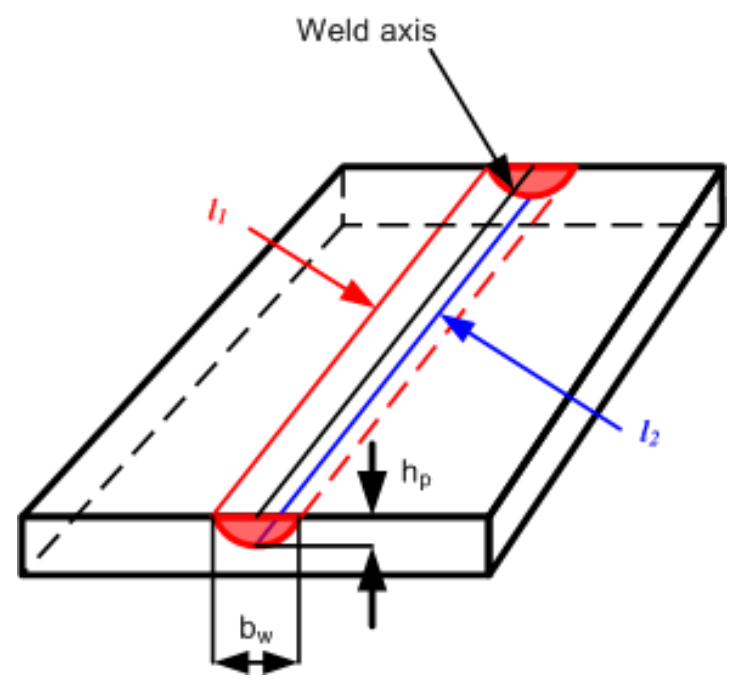

Fig.4. Lines passing through the points representing the width of the weld and the depth of penetration.

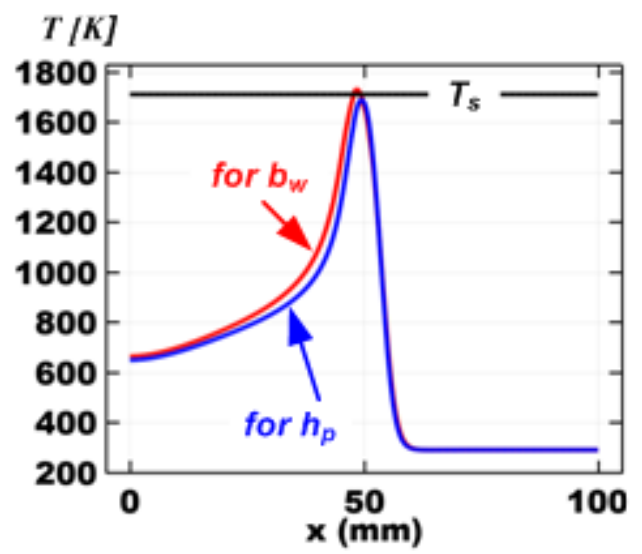

Fig.5. Temperature on the lines passing through the control points.

\section{EXPERIMENTAL RESULTS.}

To verify the operability of the proposed heat source and methodology for calibration of the heat model, experiments were performed by TIG welding of steel AISI 304. The chemical composition of the base metal is given in Table 2. The size of the samples is $6 \times 100 \times 100[\mathrm{~mm}]$. The welding modes used and the obtained seam dimensions aregiven in Table 3. Fig. 6 shows one of the measured depths of penetration and the width of the seam [29]. For mode №5, three of the measurements used to obtain averaged results are shown.

TABLE II. CHEMICAL COMPOSITION OF BASE METAL [26].

\begin{tabular}{|c|c|c|c|c|}
\hline $\begin{array}{c}\text { alloying } \\
\text { element }\end{array}$ & $\boldsymbol{C}$ & $\boldsymbol{M n}$ & $\boldsymbol{S i}$ & $\boldsymbol{C r}$ \\
\hline $\begin{array}{c}\text { concentration } \\
\text { [wt.\%] }\end{array}$ & $\leq 0.08$ & $\leq 2.0$ & $\leq 0.75$ & $18 \div 20$ \\
\hline $\begin{array}{c}\text { alloying } \\
\text { element }\end{array}$ & $\mathbf{N i}$ & $\boldsymbol{S}$ & $\boldsymbol{P}$ & $\boldsymbol{N}$ (ppm) \\
\hline $\begin{array}{c}\text { concentration } \\
\text { [wt.\%] }\end{array}$ & $8 \div 10.5$ & $\leq 0.030$ & $\leq 0.035$ & $\leq 1100$ \\
\hline
\end{tabular}

TABLE III. WELDING MODES AND WELD DIMENSIONS.

\begin{tabular}{|c|c|c|c|c|c|}
\hline \multirow{2}{*}{$\begin{array}{c}\text { No of } \\
\text { mode }\end{array}$} & $\mathbf{I}_{\mathbf{w}}$ & $\mathbf{U}_{\mathbf{a}}$ & $\mathbf{V}_{\mathbf{w}}$ & $\mathbf{b}_{\mathbf{w}}$ & $\mathbf{h}_{\mathbf{p}}$ \\
\cline { 2 - 6 }$[\mathbf{A}]$ & {$[\mathbf{V}]$} & {$[\mathbf{c m} / \mathbf{m i n}]$} & \multicolumn{2}{|c|}{$[\mathbf{m m}]$} \\
\hline 1 & 180 & 14.9 & 30 & 7.609 & 1.44 \\
\hline 2 & 180 & 14.9 & 12 & 11.518 & 3.112 \\
\hline 3 & 80 & 10.6 & 30 & 2.801 & 0.438 \\
\hline 4 & 80 & 10.6 & 12 & 4.025 & 1.006 \\
\hline 5 & 130 & 12.7 & 21 & 6.536 & 1.082 \\
\hline
\end{tabular}

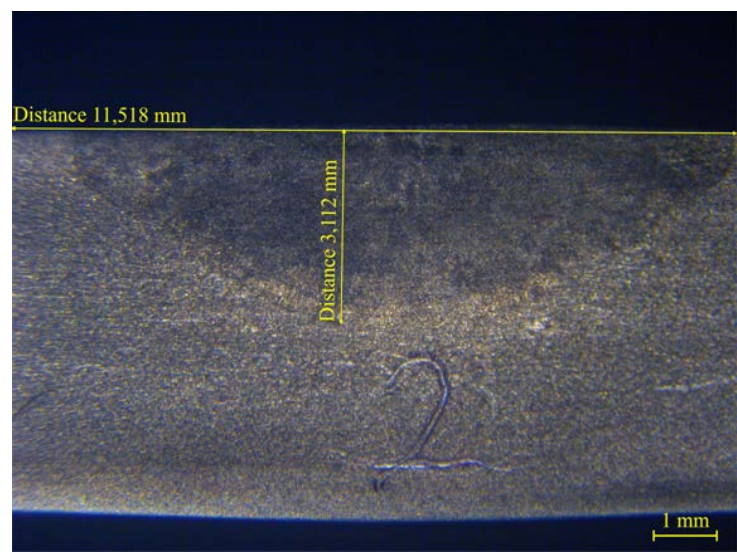

Fig.6. Measurement of the depth of penetration and the width of the weld - mode No 2

\section{TASK FORMULATION, RESULTS AND ANALYSIS.}

The geometry of the considered example is shown in Fig.7. The welding process starts from point $\mathrm{A}$ and the arc moves along the weld line to point $B$. As an initial condition, a temperature of $20^{\circ} \mathrm{C}$ is set (the ambient temperature). The heat dissipation is realized through all surfaces of the welded plates, taking into account convective and radiative heat exchange with the environment. The heat flux as a result of convective heat transfer is calculated according to Newton's law, and the radiative heat dissipation according to Stefan-Boltzmann's law. The heat source is in accordance with the described 
Environment. Technology. Resources. Rezekne, Latvia Proceedings of the $13^{\text {th }}$ International Scientific and Practical Conference. Volume 3, 348-356

model. The properties of the material are set as function depending on the temperature $[27,28]$. The latent heat of fusion is set to - 260 [J / g].

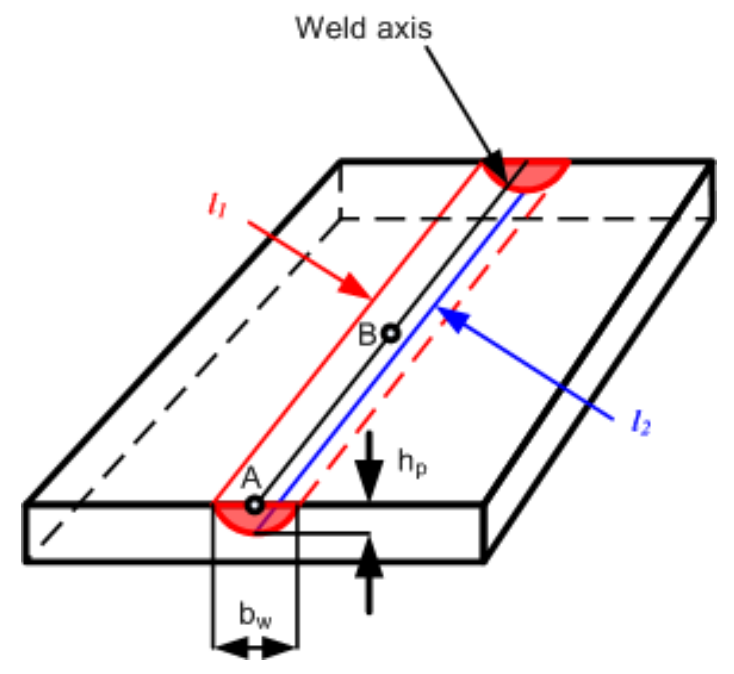

Fig. 7. Scheme of the process.

The optimization task is solved in two steps. In the first, the Monte Carlo method is applied and the objective function (4) is used. The obtained results, sorted by the value of the objective function are shown in Table 3 . The points in the vicinity of which the best results were subsequently obtained are marked in red.

TABLE IV. MONTE CARLO OPTIMIZATION RESULTS (THE 10 BEST RESULTS ARE SHOWN).

\begin{tabular}{|c|c|c|c|}
\hline$\eta$ & $\boldsymbol{\alpha}_{\text {arc }}$ & $\mathbf{r}_{\text {arc }},[\mathbf{m}]$ & Objective \\
\hline \multicolumn{4}{|c|}{ Mode No 1} \\
\hline 0.62676 & 0.139 & 0.0075832 & $5.46 \mathrm{E}-04$ \\
\hline 0.6094 & 0.13694 & 0.0073976 & 5.72E-04 \\
\hline 0.62289 & 0.28289 & 0.0071283 & 0.0010461 \\
\hline 0.61545 & 0.23455 & 0.0066467 & 0.0015075 \\
\hline 0.57382 & 0.21983 & 0.0072608 & 0.0018074 \\
\hline 0.62579 & 0.22084 & 0.0068466 & 0.0019563 \\
\hline 0.59112 & 0.15505 & 0.0068379 & 0.0025963 \\
\hline 0.56749 & 0.03058 & 0.0076471 & 0.0030009 \\
\hline 0.6433 & 0.12597 & 0.0077456 & 0.0034908 \\
\hline 0.5398 & 0.27738 & 0.0059873 & 0.0039021 \\
\hline \multicolumn{4}{|c|}{ Mode No 2} \\
\hline 0.677227 & 0.172152 & 0.010408 & 1.93E-05 \\
\hline 0.677551 & 0.227982 & 0.01017 & $1.66 \mathrm{E}-04$ \\
\hline 0.673553 & 0.032447 & 0.011367 & $2.86 \mathrm{E}-04$ \\
\hline 0.676452 & 0.063054 & 0.01104 & $2.93 \mathrm{E}-04$ \\
\hline 0.673522 & 0.12447 & 0.010174 & 3.35E-04 \\
\hline 0.668108 & 0.045558 & 0.01194 & $3.47 \mathrm{E}-04$ \\
\hline 0.663445 & 0.039103 & 0.010712 & $5.68 \mathrm{E}-04$ \\
\hline 0.662133 & 0.169945 & 0.010963 & $6.36 \mathrm{E}-04$ \\
\hline 0.69563 & 0.148558 & 0.010328 & 6.91E-04 \\
\hline 0.664232 & 0.201248 & 0.01089 & $8.66 \mathrm{E}-04$ \\
\hline
\end{tabular}

\begin{tabular}{|c|c|c|c|}
\hline $\boldsymbol{\eta}$ & $\boldsymbol{\alpha}_{\text {arc }}$ & $\mathbf{r}_{\text {arc }},[\mathbf{m}]$ & Objective \\
\hline \multicolumn{4}{|c|}{ Mode No 3 } \\
\hline 0.50787 & 0.16785 & 0.0028655 & 0.018412 \\
\hline 0.52683 & 0.24217 & 0.002547 & 0.034804 \\
\hline 0.60598 & 0.27434 & 0.0026486 & 0.074806 \\
\hline 0.62347 & 0.20201 & 0.0029766 & 0.083158 \\
\hline $\mathbf{0 . 6 5 9 1 2}$ & $\mathbf{0 . 2 4 0 0 4}$ & $\mathbf{0 . 0 0 2 9 1 8 5}$ & $\mathbf{0 . 0 9 5 6 9 5}$ \\
\hline
\end{tabular}

\begin{tabular}{|c|c|c|c|}
\hline 0.56873 & 0.079754 & 0.0029584 & 0.10973 \\
\hline 0.5627 & 0.22405 & 0.0024966 & 0.11367 \\
\hline 0.53239 & 0.24011 & 0.0022298 & 0.13301 \\
\hline 0.69648 & 0.24806 & 0.0028376 & 0.15896 \\
\hline 0.57409 & 0.22704 & 0.0023784 & 0.16116 \\
\hline \multicolumn{4}{|c|}{ Mode No 4 } \\
\hline 0.60604 & 0.024693 & 0.0039079 & 0.00019048 \\
\hline 0.57302 & 0.29392 & 0.0025921 & 0.00041417 \\
\hline 0.60379 & 0.18183 & 0.003491 & 0.0005629 \\
\hline $\mathbf{0 . 6 0 1 4 4}$ & $\mathbf{0 . 0 4 5 4 7 6}$ & $\mathbf{0 . 0 0 3 4 6 0 5}$ & $\mathbf{0 . 0 0 1 2 5 4 1}$ \\
\hline 0.57667 & 0.16285 & 0.0036141 & 0.0019396 \\
\hline 0.553 & 0.1964 & 0.0028921 & 0.002158 \\
\hline 0.56408 & 0.11388 & 0.0037442 & 0.0027833 \\
\hline 0.58814 & 0.15727 & 0.0029328 & 0.0028145 \\
\hline 0.54868 & 0.11754 & 0.0036368 & 0.0036115 \\
\hline 0.6 & 0.15 & 0.003 & 0.0041204 \\
\hline \multicolumn{5}{|c|}{ Mode No 5 } \\
\hline 0.69837 & 0.27549 & 0.0058725 & 0.002596 \\
\hline 0.64512 & 0.13544 & 0.0064706 & 0.002700 \\
\hline 0.65704 & 0.25307 & 0.0069043 & 0.003926 \\
\hline 0.62645 & 0.13075 & 0.0063511 & 0.004416 \\
\hline $\mathbf{0 . 6 3 1 7 9}$ & $\mathbf{0 . 2 8 6 9 6}$ & $\mathbf{0 . 0 0 6 3 0 7 2}$ & $\mathbf{0 . 0 0 4 5 2 2}$ \\
\hline 0.61746 & 0.10342 & 0.0069153 & 0.005871 \\
\hline 0.63154 & 0.25310 & 0.0067578 & 0.006330 \\
\hline 0.59855 & 0.21107 & 0.0057579 & 0.006370 \\
\hline 0.60833 & 0.17786 & 0.0066699 & 0.007518 \\
\hline 0.59348 & 0.01467 & 0.0068286 & 0.009056 \\
\hline
\end{tabular}

Within the second step of the optimization process in the vicinity of the five points with the best result from the first one optimization was performed using the objective function (3). One such result is shown in Table 5. As final results for the value of the calibration parameters are accepted those in which within the second step of the optimization process the lowest values of the objective function are reached (Table 6). The obtained solutions are illustrated in Fig.8. Comparing the data from Table 3 and Table 6, it can be said that for the considered cases the effective radius of the arc is approximately equal to the experimentally obtained width of the weld.

TABLE V. SEQUENCE OF THE OPTIMIZATION PROCESS.

\begin{tabular}{|c|c|c|c|c|}
\hline No & $\boldsymbol{\eta}$ & $\boldsymbol{\alpha}_{\text {arc }}$ & $\mathbf{r}_{\text {arc }},[\mathbf{m}]$ & Objective \\
\hline $\mathbf{1}$ & 0.60000 & 0.05000 & 0.00346 & 0.0018896 \\
\hline $\mathbf{2}$ & 0.60000 & 0.06200 & 0.00346 & 0.0012531 \\
\hline $\mathbf{3}$ & 0.60000 & 0.06680 & 0.00346 & 0.0010112 \\
\hline $\mathbf{4}$ & 0.60000 & 0.06680 & 0.00386 & $3.85 \mathrm{E}-04$ \\
\hline $\mathbf{5}$ & 0.60000 & 0.06200 & 0.00386 & $4.78 \mathrm{E}-04$ \\
\hline $\mathbf{6}$ & 0.62832 & 0.06680 & 0.00386 & 0.0022941 \\
\hline $\mathbf{7}$ & 0.57168 & 0.06680 & 0.00386 & 0.0026606 \\
\hline $\mathbf{8}$ & 0.60000 & 0.06872 & 0.00386 & $3.97 \mathrm{E}-04$ \\
\hline $\mathbf{9}$ & 0.60000 & 0.06488 & 0.00386 & $3.72 \mathrm{E}-04$ \\
\hline $\mathbf{1 0}$ & 0.60000 & 0.06296 & 0.00386 & $3.64 \mathrm{E}-04$ \\
\hline $\mathbf{1 1}$ & 0.60000 & 0.05912 & 0.00386 & $3.43 \mathrm{E}-04$ \\
\hline $\mathbf{1 2}$ & 0.60000 & 0.05144 & 0.00386 & $3.14 \mathrm{E}-04$ \\
\hline $\mathbf{1 3}$ & 0.60000 & 0.03608 & 0.00386 & $3.21 \mathrm{E}-04$ \\
\hline $\mathbf{1 4}$ & 0.60000 & 0.06680 & 0.00386 & $3.85 \mathrm{E}-04$ \\
\hline
\end{tabular}

TABLE V - conti nued

\begin{tabular}{|c|c|c|c|c|}
\hline No & $\boldsymbol{\eta}$ & $\boldsymbol{\alpha}_{\text {arc }}$ & $\mathbf{r}_{\text {arc }},[\mathbf{m}]$ & Objective \\
\hline $\mathbf{1 5}$ & 0.60000 & 0.05758 & 0.00386 & $3.29 \mathrm{E}-04$ \\
\hline $\mathbf{1 6}$ & 0.60000 & 0.04530 & 0.00386 & $2.55 \mathrm{E}-04$ \\
\hline $\mathbf{1 7}$ & 0.60000 & 0.03915 & 0.00386 & $3.35 \mathrm{E}-04$ \\
\hline $\mathbf{1 8}$ & 0.60000 & 0.04530 & 0.00335 & 0.0027515 \\
\hline
\end{tabular}




\begin{tabular}{|c|c|c|c|c|}
\hline 19 & 0.63625 & 0.04530 & 0.00386 & 0.0054476 \\
\hline 20 & 0.56375 & 0.04530 & 0.00386 & 0.0034804 \\
\hline 21 & 0.60000 & 0.04775 & 0.00386 & 2.63E-04 \\
\hline 22 & 0.60000 & 0.04284 & 0.00386 & $2.47 \mathrm{E}-04$ \\
\hline 23 & 0.60000 & 0.04038 & 0.00386 & 3.43E-04 \\
\hline 24 & 0.60000 & 0.04284 & 0.00365 & 7.23E-05 \\
\hline 25 & 0.60000 & 0.04284 & 0.00345 & 0.0012105 \\
\hline 26 & 0.63625 & 0.04284 & 0.00365 & 0.0086474 \\
\hline 27 & 0.56375 & 0.04284 & 0.00365 & 0.0019852 \\
\hline 28 & 0.60000 & 0.04530 & 0.00365 & 4.25E-05 \\
\hline 29 & 0.60000 & 0.04775 & 0.00365 & 5.85E-05 \\
\hline 30 & 0.60000 & 0.04530 & 0.00386 & $2.55 \mathrm{E}-04$ \\
\hline 31 & 0.60000 & 0.04530 & 0.00345 & 0.0012202 \\
\hline 32 & 0.63625 & 0.04530 & 0.00365 & 0.0081506 \\
\hline 33 & 0.56375 & 0.04530 & 0.00365 & 0.0019982 \\
\hline 34 & 0.57046 & 0.04530 & 0.00368 & 0.0014195 \\
\hline 35 & 0.58818 & 0.04530 & 0.00366 & 1.79E-04 \\
\hline 36 & 0.59527 & 0.04530 & 0.00366 & $1.21 \mathrm{E}-05$ \\
\hline 37 & 0.59745 & 0.04530 & 0.00366 & $2.17 \mathrm{E}-07$ \\
\hline 38 & 0.61195 & 0.04530 & 0.00366 & $8.00 \mathrm{E}-04$ \\
\hline 39 & 0.58295 & 0.04530 & 0.00366 & 4.92E-04 \\
\hline 40 & 0.59745 & 0.04628 & 0.00366 & 5.31E-07 \\
\hline 41 & 0.59745 & 0.04431 & 0.00366 & 7.89E-08 \\
\hline 42 & 0.59745 & 0.04333 & 0.00366 & 3.15E-08 \\
\hline 43 & 0.59745 & 0.04136 & 0.00366 & $4.50 \mathrm{E}-07$ \\
\hline 44 & 0.59745 & 0.04333 & 0.00382 & 3.02E-04 \\
\hline 45 & 0.59745 & 0.04333 & 0.00349 & $4.27 \mathrm{E}-04$ \\
\hline 46 & 0.62645 & 0.04333 & 0.00366 & 0.00359 \\
\hline 47 & 0.56845 & 0.04333 & 0.00366 & 0.0017057 \\
\hline 48 & 0.59745 & 0.04530 & 0.00366 & 2.17E-07 \\
\hline 49 & 0.59684 & 0.04333 & 0.00366 & 3.24E-06 \\
\hline 50 & 0.59721 & 0.04333 & 0.00366 & $1.38 \mathrm{E}-05$ \\
\hline 51 & 0.59740 & 0.04333 & 0.00366 & $4.80 \mathrm{E}-06$ \\
\hline 52 & 0.60905 & 0.04333 & 0.00366 & $4.61 \mathrm{E}-04$ \\
\hline 53 & 0.58585 & 0.04333 & 0.00366 & $3.18 \mathrm{E}-04$ \\
\hline 54 & 0.59745 & 0.04412 & 0.00366 & $5.87 \mathrm{E}-08$ \\
\hline 55 & 0.59745 & 0.04254 & 0.00366 & $1.55 \mathrm{E}-07$ \\
\hline 56 & 0.59745 & 0.04333 & 0.00372 & 1.95E-05 \\
\hline 57 & 0.59745 & 0.04333 & 0.00359 & $1.16 \mathrm{E}-04$ \\
\hline 58 & 0.60209 & 0.04333 & 0.00366 & 5.93E-05 \\
\hline 59 & 0.59281 & 0.04333 & 0.00366 & 5.05E-05 \\
\hline 60 & 0.59745 & 0.04333 & 0.00366 & 3.15E-08 \\
\hline
\end{tabular}

TABLE VI. RESULTS OF THE OPTIMIZATION PROCESS

\begin{tabular}{|c|c|c|c|c|}
\hline $\begin{array}{c}\text { No of } \\
\text { mode }\end{array}$ & $\boldsymbol{\eta}$ & $\boldsymbol{\alpha}_{\text {arc }}$ & $\mathbf{r}_{\text {arc }}$ [mm] & Objective \\
\hline 1 & 0.61848 & 0.16669 & 7.58 & $7.53 \mathrm{E}-08$ \\
\hline 2 & 0.68373 & 0.18469 & 10.41 & $1.39 \mathrm{E}-07$ \\
\hline 3 & 0.53322 & 0.26737 & 2.9766 & $1.25 \mathrm{E}-05$ \\
\hline 4 & 0.59745 & 0.04333 & 3.6567 & $3.15 \mathrm{E}-08$ \\
\hline 5 & 0.67603 & 0.2969 & 5.8135 & $6.29 \mathrm{E}-05$ \\
\hline
\end{tabular}

In order to check whether the solutions obtained in the described way adequately represent the temperature field, the numerical results are compared with the experimental ones. Fig. $9 \div 12$ shows a comparison for the first 4 modes. Fig. 13 shows the comparison of the calculated result with the experimental ones for three of the welds produced with mode 5. From these figures it can be seen that the form of penetration predicted by the model coincides well with the experimentally obtained one.
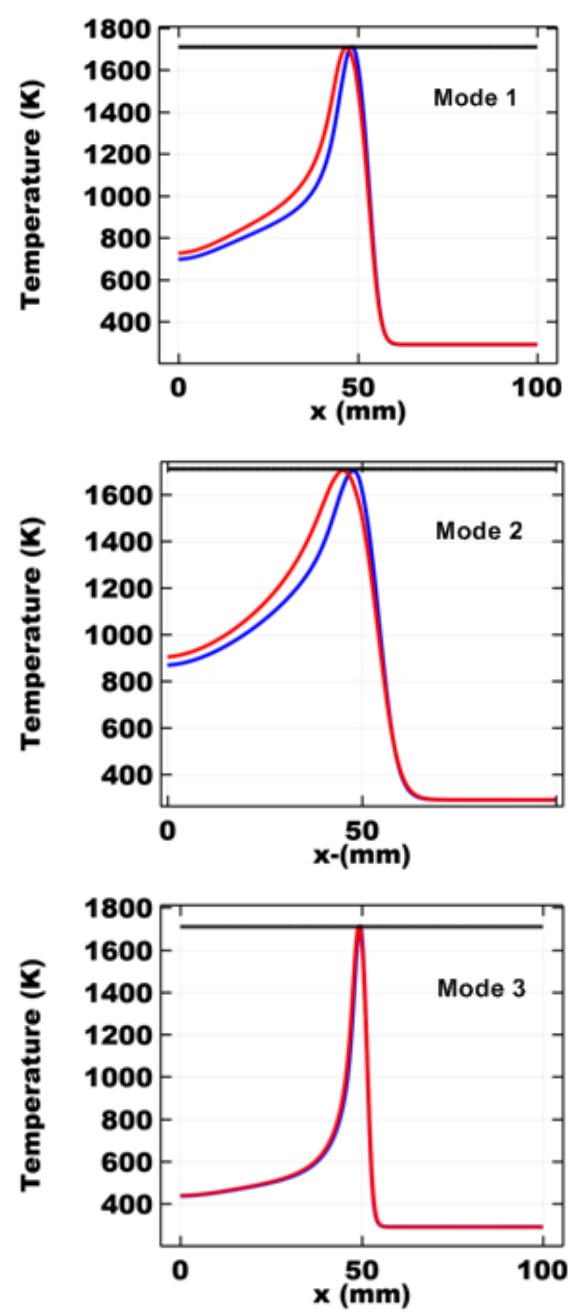

Fig.8. Solidus temperature (black) and temperature along the control lines - 11 (blue) and 12 (red) at the last moment for which the calculation was performed.

\section{CONCLUTIONS.}

A new model of the heat source suitable for TIG welding is proposed. As calibration parameters used by the model are: efficiency, the effective radius of heating of the product from the arc and the coefficient accounting the heat source concentration. In the framework of the conducted researches it was established that the effective radius of the arc is approximately equal to the obtained width of the bead. A method of model calibration based on solving an optimization problem has been developed. The form of penetration predicted by the model was compared with experimental results and was shown to have a good match. 
Environment. Technology. Resources. Rezekne, Latvia Proceedings of the $13^{\text {th }}$ International Scientific and Practical Conference. Volume 3, 348-356
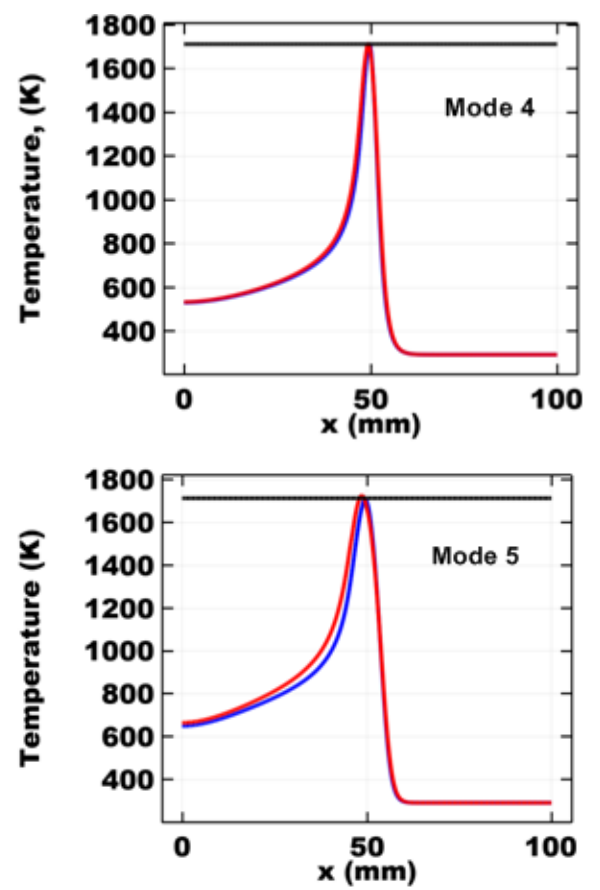

Fig.8. - continued

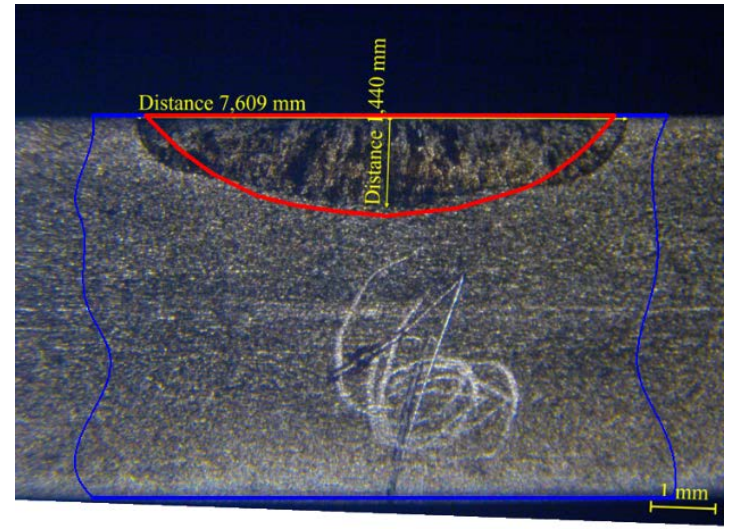

Fig.9. Comparison of the obtained results for mode No1

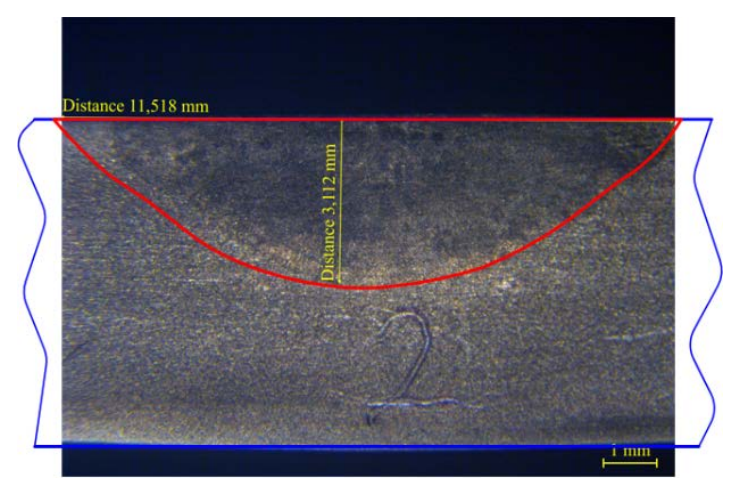

Fig.10. Comparison of the obtained results for mode No2

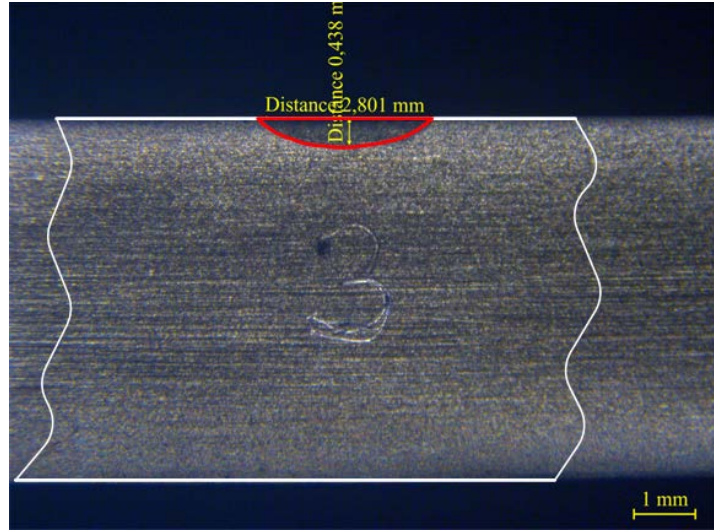

Fig.11. Comparison of the obtained results for mode No3

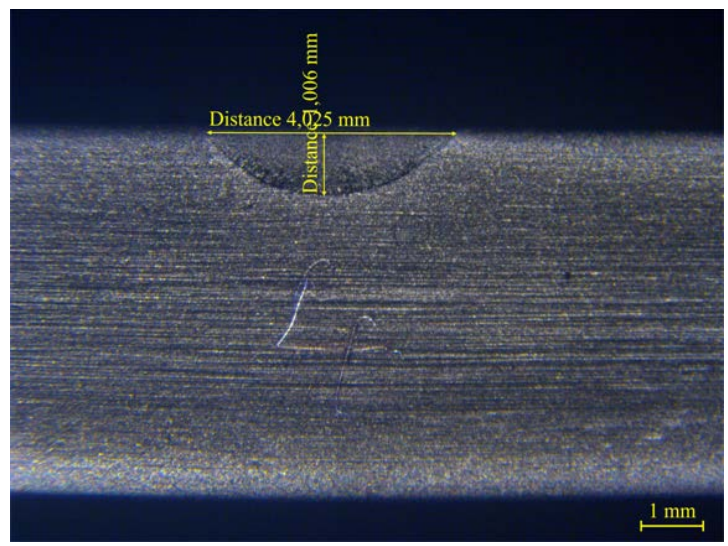

Fig.12. Comparison of the obtained results for mode No4

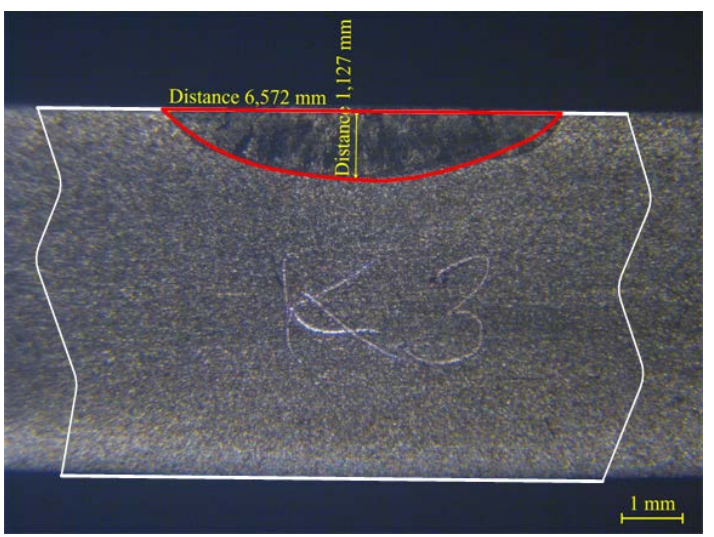



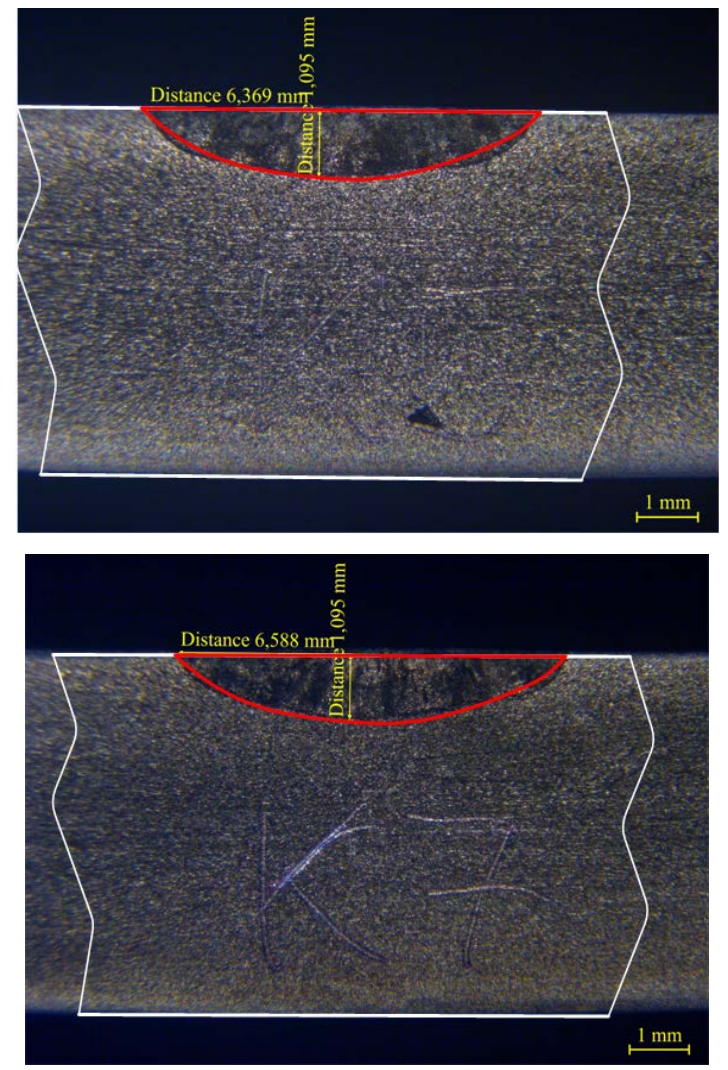

Fig.13. Comparison of the obtained results for mode No5

\section{REFERENCES}

[1] Huang Pengfei, Li Yan , Lu Yangyang and Lu Zhenyang, Numerical simulation of the temperaturbe filed in fixed-TIG welding pool, 2011 International Conference on Modeling, Simulation and Control, IPCSIT vol.10 (2011) (C) (2011) IACSIT Press, Singapore

[2] De Freitas Teixeira, P. R., De Araújo, D. B., \& Da Cunha, L. A. B. (2014). Study of the gaussian distribution heat source model applied to numerical thermal simulations of tig welding processes. Ciencia y Engenharia/ Science and Engineering Journal, 23(1), 115-122. doi:10.14393/19834071.2014.26140

[3] LIU, H. and NIU, L., 2015. Finite element simulation research on medium plate multi-pass welding temperature field. The Open Mechanical Engineering Journal, 2015, Volume 9, pp.786-790

[4] ISMAIL, M.I.S. and AFIEQ, W.M.A., 2016. Thermal analysis on a weld joint of aluminium alloy in gas metal arc welding. Advances in Production Engineering and Management, Volume 11 Number 1 | March 2016 | pp 29-37, ISSN18546250

[5] ZHANG, M., ZHOU, Y., HUANG, C., CHU, Q., ZHANG, W. and LI, J., 2018. Simulation of temperature distribution and microstructure evolution in the molten pool of GTAW Ti-6Al-4V alloy. Materials 2018, 11(11), 2288; https://doi.org/10.3390/ma11112288

[6] Wróbel, J., \& Kulawik, A. (2019). Prediction of the superficial heat source parameters for TIG heating process using FEM and ANN modeling. Entropy, 21(10) doi:10.3390/e21100954

[7] YAMANE, S., YAMAZAKI, T., KANETA, T., NAKAJIMA, T. and YAMAMOTO, H., 2011. Experiment and numerical simulation in temperature distribution and welding distortion in GMA welding. Yosetsu Gakkai Ronbunshu/Quarterly Journal of the Japan Welding Society, 29(3), (2011) pp. 31s-34s., https://doi.org/10.2207/qjjws.29.31s

[8] BJELIĆ, M.B., KOVANDA, K., KOLARIK, L., VUKIĆEVIĆ, M.N. and RADIČEVIĆ, B.S., 2016. Numerical modeling of two- dimensional heat-transfer and temperature-based calibration using simulated annealing optimization method: Application to gas metal arc welding. Thermal Science, 20(2), pp. 655-665, doi:10.2298/TSCI150415127B

[9] Alexandre Campos Bezerra, Domingos Alves Rade and Américo Scotti, FINITE ELEMENT SIMULATION OF TIG WELDING: THERMAL ANALYSIS, 18th International Congress of Mechanical Engineering, November 6-11, 2005, Ouro Preto, MG, Proceedings of COBEM 2005

[10] M. Afzaal Malik, M. Ejaz Qureshi and Naeem Ullah Dar, Numerical Simulation of Arc Welding Investigation of various Process and Heat Source Parameters, MED UET Taxila (2007), pp $127 \div 142$

[11] Pablo Batista Guimarães et all, OBTAINING TEMPERATURE FIELDS AS A FUNCTION OF EFFICIENCY IN TIG WELDING BY NUMERICAL MODELING, 21st Brazilian Congress of Mechanical Engineering October 24-28, 2011, Natal, RN, Brazil, $\begin{array}{lll}\text { Proceedings of 2011, DOBEM } & \end{array}$ http://dx.doi.org/10.5380/reterm.v10i1-2.61952

[12] Djarot B. Darmadi, Validating the accuracy of heat source model via temperature histories and temperature field in bead-on-plate welding, International Journal of Engineering \& Technology October 2011 IJENS Vol: 11 No: 05

[13] DA NÓBREGA, J., SILVA, D., ARAÚJO, B., DE MELO, R., MACIEL, T., SILVA, A. and DOS SANTOS, N., 2014. Numerical evaluation of multipass welding temperature field in API 5L X80 steel welded joints. International Journal of Multiphysics, 8(3), pp. 337-348.

[14] PAMNANI, R., VASUDEVAN, M., JAYAKUMAR, T., VASANTHARAJA, P. and GANESH, K.C., 2016. Numerical simulation and experimental validation of arc welding of DMR249A steel. Defence Technology, Volume 12, Issue 4, August 2016, Pages 305-315, https://doi.org/10.1016/j.dt.2016.01.012

[15] Piekarska, W., \& Rek, K. (2017). Numerical analysis and experimental research on deformation of flat made of TIG welded 0H18N9 steel. Paper presented at the Procedia Engineering, , 177 182-187. doi:10.1016/j.proeng.2017.02.217 Retrieved from www.scopus.com

[16] Rui-ying Li, Chunyu Chen, Dawei Zhao and Chunmei Wu, Determination and Application of Double Ellipsoid Heat Source Model, International Conference on Material Science, Energy and Environmental Engineering (MSEEE 2017), Advances in Engineering Research, volume 125 , pp. $267 \div 270$, https://doi.org/10.2991/mseee-17.2017.49

[17] YAN, C., JIANG, H., WU, L., KAN, C. and YU, W., 2018. Numerical simulation of temperature field in multiple-wire submerged arc welding of X80 pipeline steel, IOP Conference Series: Earth and Environmental Science 108 022048, 2018

[18] P.Ferro, F. Berto, F. Bonollo and R.Montanari, Experimental and numerical analysis of TIG-dressing applied to a steel weldment, Procedia Structural Integrity Volume 9, 2018, Pages 64-70, https://doi.org/10.1016/j.prostr.2018.06.012

[19] Huang, H., Yin, X., Feng, Z., \& Ma, N. (2019). Finite element analysis and in-situ measurement of out-of-plane distortion in thin plate TIG welding. Materials, 12(1) doi:10.3390/ma12010141

[20] Matuszewski, M. (2019). Modeling of 3D temperature field in butt welded joint of 6060 alloy sheets using the ANSYS program. Paper presented at the IOP Conference Series: Materials Science and Engineering, , 659(1) doi:10.1088/1757-899X/659/1/012034

[21] ZUO, S., WANG, Z., WANG, D., DU, B., CHENG, P., YANG, Y., ZHANG, P. and LANG, N., 2020. Numerical simulation and experimental research on temperature distribution of fillet welds. Materials 2020, 13(5), 1222; https://doi.org/10.3390/ma13051222

[22] A.MOARREFZADEH and M.A.SADEGHI, Numerical Simulation of Thermal Profile By Gas Tungsten Arc Welding Process in Copper, WSEAS TRANSACTIONS on HEAT and MASS TRANSFER, Issue 3, Volume 5, July 2010, ISSN: 1790504

[23] SAADLAOUI, Y., FEULVARCH, É., DELACHE, A., LEBLOND, J.-. and BERGHEAU, J.-., 2018. A new strategy for 
Environment. Technology. Resources. Rezekne, Latvia Proceedings of the $13^{\text {th }}$ International Scientific and Practical Conference. Volume 3, 348-356

the numerical modeling of a weld pool. Comptes Rendus Mecanique, Volume 346, Issue 11, November 2018, Pages 9991017, https://doi.org/10.1016/j.crme.2018.08.007.

[24] FLINT, T.F. and SMITH, M.C., 2019. HEDSATS: High energy density semi-analytical thermal solutions. SoftwareX, Volume 10, July-December 2019,

100243 , https://doi.org/10.1016/j.softx.2019.100243

[25] Karim Agrebi, Asma Belhadj and Mahmoud Bouhafs, THREEDIMENSIONAL NUMERICAL SIMULATION OF A GAS TUNGSTEN ARC WELDING PROCESS, IJTech 2019, International Journal of Technology 10(4) pp. 689-699, ISSN 20869614, DOI: https://dx.doi.org/10.14716/ijtech.v10i4.1849

[26] https://www.acerinox.com/en/productos/stainless-steel-grade/EN1.4301---AISI-304-00001/

[27] (http://asm.matweb.com/search/SpecificMaterial.asp?bassnum=M Q304A)
[28] https://www.researchgate.net/figure/a-Thermal-conductivity-kTas-a-function-of-temperature-for-SS-304-40-bSpecific fig2 318688478

[29] Manahil Tongov, Rayna Dimitrova and Konstantin Konstantinov, Bead formation research in TIG welding of AISI 304 steel, 9-TH INTERNATIONAL SCIENTIFIC CONFERENCE "ENGINEERING, TECHNOLOGIES AND SYSTEMS", TECHSYS 2020, 14-16 May, Plovdiv, Bulgaria, IOP Conf. Series: Materials Science and Engineering 878 (2020) 012054, doi:10.1088/1757-899X/878/1/012054

Acknowledgments:

This work was made possible by a project KP-06-N37/31, funded by the NSF. 